Check for updates

Cite this: RSC Adv., 2018, 8, 25127

Received 13th April 2018

Accepted 8th July 2018

DOI: $10.1039 / c 8 r a 03157 f$

rsc.li/rsc-advances

\section{Effect of biodegradable magnesium-copper coatings on bone integration based on the porous structures in a rabbit model}

\begin{abstract}
Yurun Ding, $\dagger^{\mathrm{a}}$ Zhe Du, $\dagger^{\mathrm{b}}$ Zhonglin Zhu, ${ }^{\mathrm{c}}$ Xiaoming $\mathrm{Yu}^{\mathrm{d}}$ and You Wang (D) *a
Biodegradable magnesium (Mg)-copper (Cu) coatings are promising in orthopedic implants to enhance osteogenesis. The present study aimed to compare the osteogenic effect of $\mathrm{Mg}-\mathrm{Cu}$ coating and noncoating implants using a rabbit model. $\mathrm{Mg} / \mathrm{Mg}-\mathrm{Cu}$ coating of porous Ti6Al4V alloys was performed by the arc ion plating method. Five porous implants (smooth, porous, $\mathrm{Mg}$ coated, $\mathrm{Mg}-0.1 \mathrm{Cu}$ coated, and $\mathrm{Mg}-0.7 \mathrm{Cu}$ coated) were implanted into the distal femurs of the rabbits. The rabbits were sacrificed after one and two months, respectively, and the distal femurs with the implants were analyzed via microcomputed tomography (CT), double fluorescent labeling, and hard tissue biopsy to evaluate their osteogenic effect. During the two months of observation, the $\mathrm{Mg} / \mathrm{Mg}-\mathrm{Cu}$ coatings exhibited no advantages when compared with the bare porous structures in terms of bone integration; however, the porous structures were more conducive for bone ingrowth than the smooth implants. The osteogenic application of $\mathrm{Mg}-\mathrm{Cu}$ coated orthopedic implants is worth further investigation. Furthermore, due to its long-term antibacterial ability, the biodegradable $\mathrm{Mg}$-Cu coatings are promising in orthopedic applications.
\end{abstract}

\section{Introduction}

Biodegradable magnesium ( $\mathrm{Mg}$ ) implants have been widely used in both in vitro and in vivo studies, as they can avoid repeated removal, thus reducing cost and treatment risk. They are becoming potential metal substitutes for the existing implant materials. ${ }^{\mathbf{1}, 2}$ Furthermore, the main limitation for its clinical application is the rapid initial degradation of $\mathrm{Mg}$ and its biomechanical strength. ${ }^{3}$ It is generally considered that the 416 week degradation time is suitable for $\mathrm{Mg}$ implants, ${ }^{4}$ which can ensure the stability and healing of fracture.

From a materials perspective, copper $(\mathrm{Cu})$ is one of the antibacterial metals, and studies have reported that the deficiency of $\mathrm{Cu}$ ions can affect bone induction and osteoclast activity. ${ }^{5}$ Copper alloys can accelerate the degradation of $\mathrm{Mg}$; therefore, the rate of $\mathrm{Mg}$ degradation can be adjusted by different $\mathrm{Cu}$ concentrations. ${ }^{6}$ An in vitro study has reported that biodegradable $\mathrm{Mg}-\mathrm{Cu}$ alloys have long-term antibacterial

${ }^{a}$ Department of Bone and Joint Surgery, Renji Hospital, School of Medicine, Shanghai Jiaotong University, 145 Middle Shandong Road, Shanghai, China, 200001. E-mail: drwangyou@163.com; mcfee2002@163.com; Fax: +862153882181; Tel: $+862153882181$

${ }^{b}$ Trauma and Emergency Center, Peking University People's Hospital, Beijing, China. E-mail:drdz01@163.com

'Jiangsu OKANI Medical Technology Co., Ltd, Soochow, China.E-mail: ezhuzhonglin@ 163.com

${ }^{d}$ Institute of Metal Research, Chinese Academy of Science, Shenyang, China. E-mail: xmyu@imr.ac.cn

$\dagger$ Yurun Ding and Zhe Du contributed equally to this work. effects. ${ }^{6}$ Besides antiseptic effects, it is reported that a high concentration of $\mathrm{Mg}$ can significantly activate bone cells and improve the activity of osteoblasts and osteoclasts in vitro. ${ }^{7,8}$ The degradable feature and its potential effects of antibiosis and bone remodeling imply another possible use of $\mathrm{Mg}$ or $\mathrm{Mg}$ alloys as a surface coating material of biologically fixed implants. Therefore, $\mathrm{Mg}-\mathrm{Cu}$ coatings on porous Ti6Al4V implants might exhibit antibacterial function, thus, preventing early periprosthetic infections. However, whether $\mathrm{Mg}-\mathrm{Cu}$ coatings influence bone ingrowth into porous implants in vivo is not known. In the present study, we deposited different proportions of $\mathrm{Mg}$ and $\mathrm{Cu}$ coatings on porous implant surfaces by arc ion plating, and introduced them into animal models to compare the effect of $\mathrm{Mg}$ and $\mathrm{Cu}$ coatings on bone ingrowth based on porous structures. We hypothesized that $\mathrm{Mg}-\mathrm{Cu}$ coatings can promote bone integration when compared with the non-coated controls.

\section{Materials and methods}

\section{Ti6Al4V implants}

The cylindrical implants were provided by the Jiangsu Okani Medical Technology (Soochow, Jiangsu, China). As shown in Fig. 1, there are five types of implants, including smooth (no coated), porous (porous structures without coating), $\mathrm{Mg}$ (porous implant with $\mathrm{Mg}$ coating), $\mathrm{Mg}-0.1 \mathrm{Cu}$ (the proportion of $\mathrm{Mg}$ and $\mathrm{Cu}$ is $1: 0.1$ ), and $\mathrm{Mg}-0.7 \mathrm{Cu}$ implants (the proportion of $\mathrm{Mg}$ and $\mathrm{Cu}$ is $1: 0.7$ ) (Fig. 1). All the implants were prepared by $3 \mathrm{D}$ printing with Ti6Al4V, and the porous structures were $8 \mathrm{~mm}$ long and $4.2 \mathrm{~mm}$ wide. There were two sites with $1 \mathrm{~mm}$ porous 


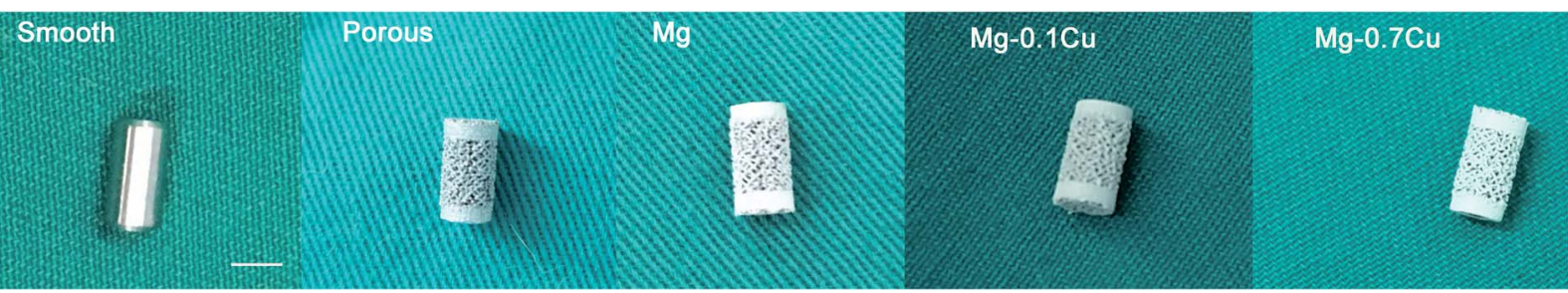

Fig. 1 General view of the implant. From left to right, smooth, porous, $\mathrm{Mg}, \mathrm{Mg}-0.1 \mathrm{Cu}$, and $\mathrm{Mg}-0.7 \mathrm{Cu}$ implants (bar $=5 \mathrm{~mm}$ )

structures at both ends of the implants. The deposition of $\mathrm{Mg}$ and $\mathrm{Mg}-\mathrm{Cu}$ coating on Ti6Al4V alloy was performed by the arc ion plating method. The implants were sterilized by irradiation and packed under sterile environmental condition.

\section{Animals}

Eighty female rabbits weighing $2.5-3.0 \mathrm{~kg}$ were procured from the Animal Experimental Center of the Renji Hospital (Shanghai Jiaotong University, Shanghai, China). They were randomly assigned to two groups, one group with an observation time of one month and the other group with two months. Each group was divided into five subgroups according to the implants-smooth $(n=8)$, porous $(n=8), \mathrm{Mg}$ coated $(n=8)$, $\mathrm{Mg}-0.1 \mathrm{Cu}$ coated $(n=8)$, and $\mathrm{Mg}-0.7 \mathrm{Cu}$ coated $(n=8)$. The rabbits were maintained in a surgical research institution for one week prior to implantation. They were maintained in groups of eight per cage, with access to food and water ad libitum. All the animal procedures and experiments were approved by the Animal Ethical Committee of the Renji Hospital, Shanghai Jiaotong University, School of Medicine (Shanghai, China). All experiments were performed according to the guidelines of the National Institute of Health, and the institutional rules for the use and care of laboratory animals at the Shanghai Jiaotong University.

\section{Surgical procedures}

The rabbits were anesthetized by venous administration of ketamine $\left(10 \mathrm{mg} \mathrm{kg}^{-1}\right)$. Each rabbit was immobilized with the knee joint in the maximally flexed position, and the left leg was shaved and depilated. A channel of length $15 \mathrm{~mm}$ was drilled at the end of the distal femur (just under the trochlea) using $4 \mathrm{~mm}$ hollow drill bits, and the cylindrical implant was then inserted into the hole and embedded in the middle of the channel with a hammer. The wound was sutured by layers after irrigation. After surgery, the rabbits were housed in ventilated rooms with access to water and food. Each animal was observed and evaluated daily for their general health.

\section{Double fluorescent labeling}

To the rabbits that were observed for one month, Alizarin Red S $\left(30 \mathrm{mg} \mathrm{kg}^{-1}\right)$ (Sigma) and Calcein $\left(20 \mathrm{mg} \mathrm{kg}^{-1}\right)$ (Sigma) were intraperitoneally injected 1 and 3 weeks post operation, respectively, to label the newly forming bone. To the rabbits that were observed for two months, Alizarin Red S (30 mg kg${ }^{-1}$ ) (Sigma) and Calcein $\left(20 \mathrm{mg} \mathrm{kg}^{-1}\right)$ (Sigma) were intraperitoneally injected 3 and 6 weeks post operation. Two slices per animal were used for fluorescence observation. In each slice, two visual fields were randomly selected, and the fluorescence intensity was analyzed using the Image-pro software. ${ }^{9}$

\section{Sample preparation}

The animals were sacrificed through the intravenous injection of pentobarbital sodium overdose one and two months after surgery. The distal femurs were harvested and fixed in $4 \%$ buffered formaldehyde for histomorphometric observation and micro-CT examination.

\section{Micro-CT examination}

After sacrificing the rabbits, the distal femur from their left hind limbs was examined using a micro-CT system (SCANCO medical AG, Bassersdorf, Zurich, Switzerland) with $30 \mu \mathrm{m}$ axial slices. According to the recommended reporting guidelines for methodology, ${ }^{10,11}$ the $2 \mathrm{D}$ images of the distal femur of an adult rabbit were scanned at a voxel size of $12 \mu \mathrm{m}$. The images were acquired at $70 \mathrm{kVp}, 30 \mu \mathrm{A}$, and $300 \mathrm{~ms}$ integration time. The porous structure was defined as volume of interest 1 (VOI $1 ; 1 \mathrm{~mm}$ in width, $5.9 \mathrm{~mm}$ in height). The peripheral circular volume, which was $0.5 \mathrm{~mm}$ in diameter and $3 \mathrm{~mm}$ in height, was defined as volume of interest 2 (VOI 2). The bone density (BD) and bone volume/total volume (BV/TV) were analyzed in the VOIs 1 and 2. The 2D images of the distal femurs and 3D images of new porous (VOI 1) and peripheral (VOI 2) bones were reconstructed (Fig. 2).

\section{Hard tissue biopsy}

The distal femurs were dehydrated stepwise using 70\%, 95\%, and $100 \%$ ethanol, followed by incubation in methyl methacrylate. A Leica diamond saw (Leica SP1600) was used to cut the resin blocks into $150 \mu \mathrm{m}$ thick slices, parallel to the long axis of the femoral shaft. The sections were ground and polished to a thickness of about $50 \mu \mathrm{m}$. The specimens were stained using van Gieson's picrofuchsin. Two slices per animal were used for microscopic observation. In each slice, two visual fields were randomly observed using a light microscope $(4 \times, 10 \times$; Carl Zeiss MicroImaging GmbH, Germany).

\section{Statistical analysis}

The data were analyzed by the one-way analysis of variance (ANOVA) with least significant difference (LSD) post hoc $t$-tests. Whitney $U$ and Wilcoxon rank sum tests were used for unpaired and paired non-parametric data, respectively. Differences with $p$ $<0.05$ were considered statistically significant. 


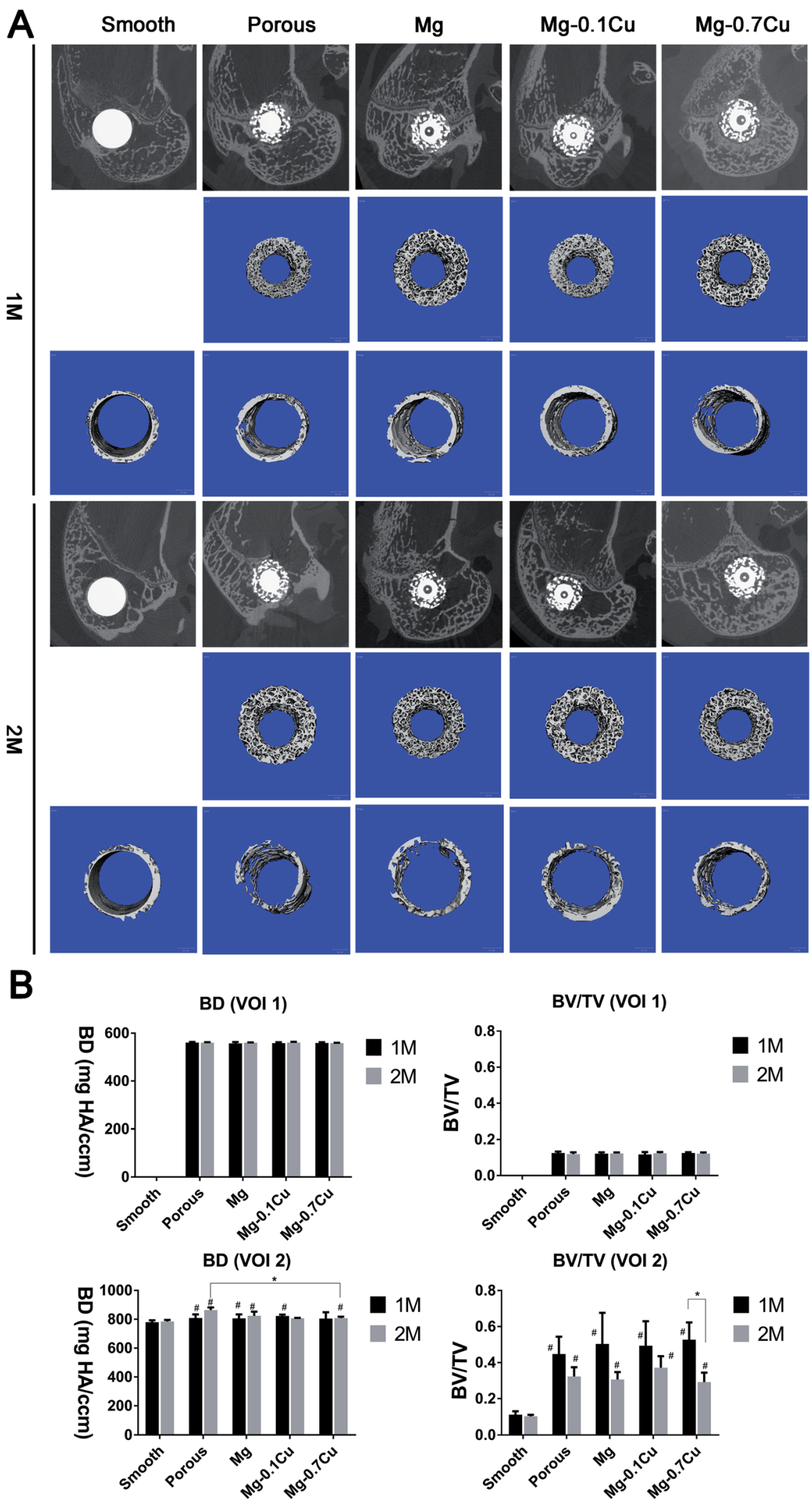

Fig. 2 Micro-CT analysis of the distal femurs with the implants after one and two months. (A) Radiological reconstruction images of the bone in the porous and peripheral regions. 2D reconstructions of the distal femurs are shown in the first row. 3D reconstructions of the bone in the porous and peripheral regions, respectively, are shown in the second and third rows. (B) The results of micro-CT analysis of bone-related parameters in volume of interests. The bars represent the mean and the error bars represent standard deviation. ${ }^{*} p<0.05$ and $\# p<0.05$ when compared with that of the smooth group at each time point. 


\section{Results}

\section{Micro-CT examination}

There was no significant difference in the BD and BV/TV values of the porous structures (VOI 1) between months 1 and 2 (Fig. 2). Moreover, there was no significant difference among the groups, except the smooth group (no VOI 1). In the peripheral area (VOI 2), the BD in the porous structure was higher than that in the smooth surface structure $(p<0.05)$, whereas there was no significant difference between the $\mathrm{Mg}$ / $\mathrm{Mg}-\mathrm{Cu}$ and porous groups $(p>0.05)$. The BV/TV value of the porous structure group was higher than that of the smooth group. Furthermore, there was no significant difference between the $\mathrm{Mg} / \mathrm{Mg}-\mathrm{Cu}$ and porous groups $(p>0.05)$, and among the different $\mathrm{Mg} / \mathrm{Mg}-\mathrm{Cu}$ groups. The $\mathrm{BV}$ of the porous structure decreased after two months; however, it was not significant $(p>0.05)$. In particular, the BV/TV value of the $\mathrm{Mg}-$ $0.7 \mathrm{Cu}$ group decreased significantly after two months when compared with that after one month $(p<0.05)$.

\section{Double fluorescent labeling}

The fluorescence intensity of the coated groups was not higher than that of the porous group in VOI $1(p>0.05)$. In the first month, the fluorescence intensity of the coated groups was marginally higher than that of the porous group in VOI 2; however, there was no significant difference $(p>0.05)$. Additionally, there was no significant difference among the different $\mathrm{Mg} / \mathrm{Mg}-\mathrm{Cu}$ content groups in VOI $2(p>0.05)$. The fluorescence intensity of porous groups (including the coated groups) was
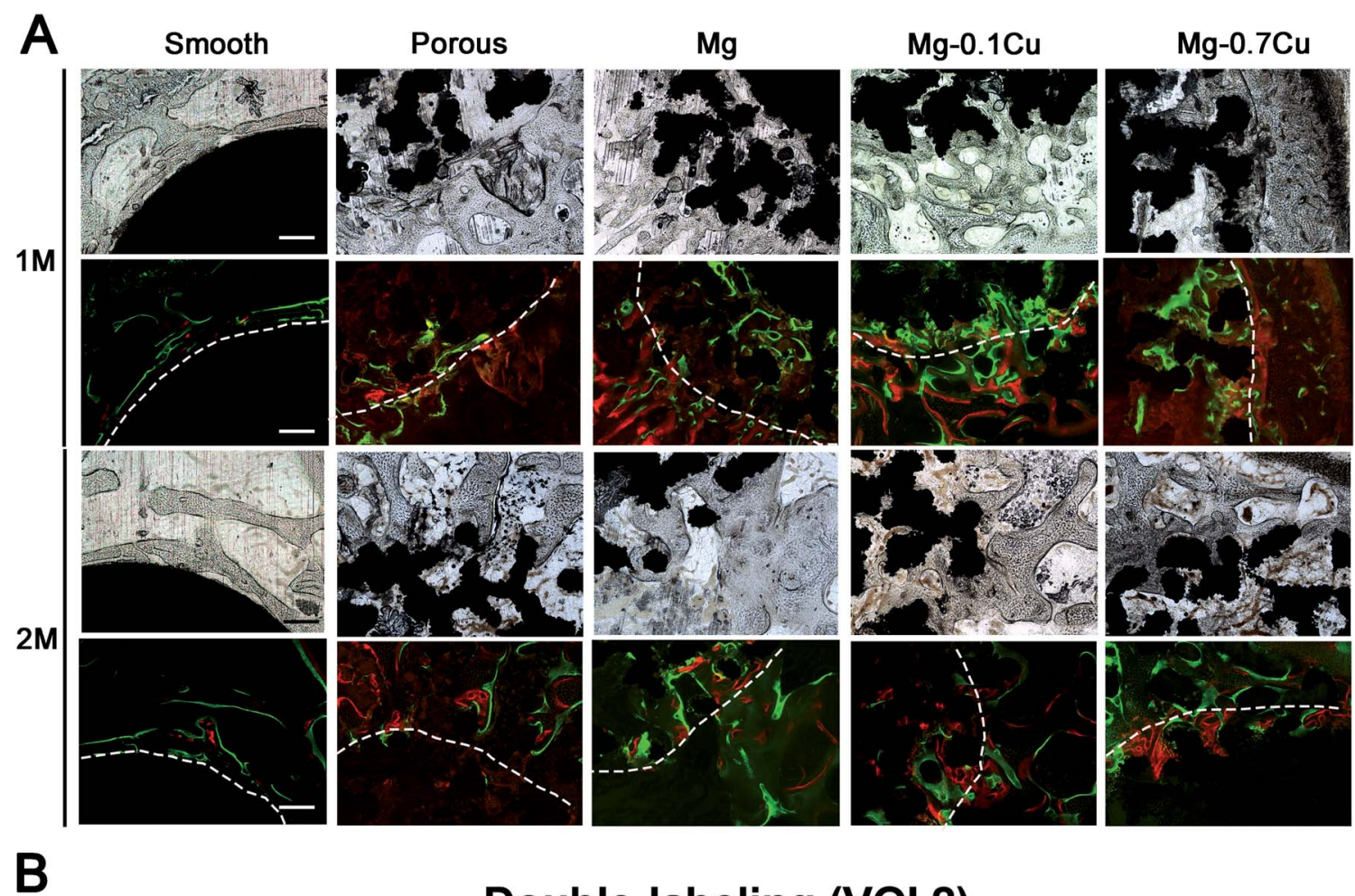

\section{Double-labeling (VOI 2)}

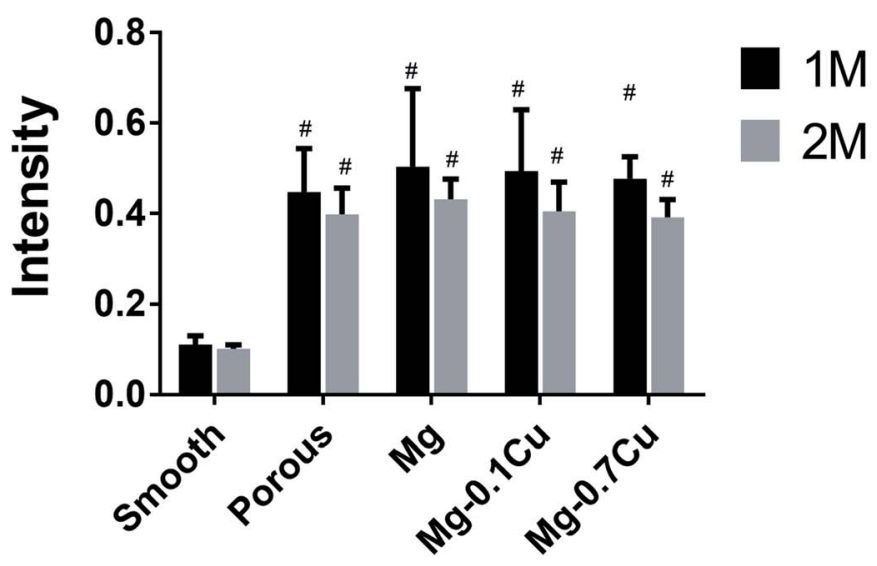

Fig. 3 Double fluorescent labeling of the distal femur with implants. (A) Tissue sections under white light and fluorescence scope. (B) Fluorescent intensity analysis. 

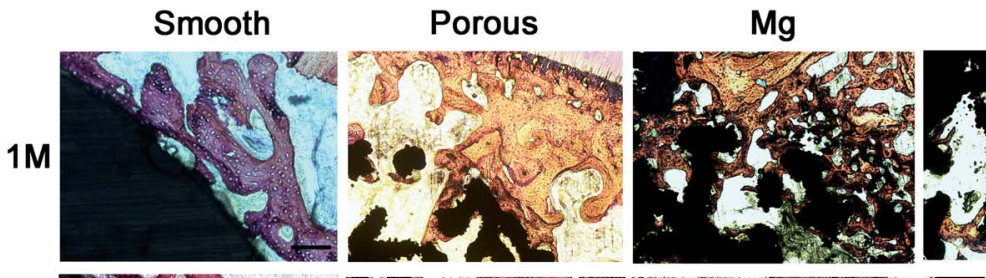

$\mathrm{Mg}-0.1 \mathrm{Cu}$

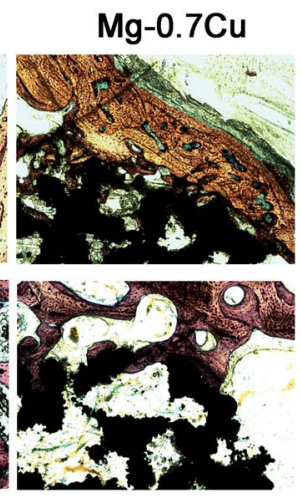

Fig. 4 Hard tissue biopsy of the distal femur after one- and two-months (magnification $40 \times$, bar $=1000 \mu \mathrm{m}$ ). The first row presents hard tissue biopsy of the distal femur from five groups after one month. The bone volume in the peripheral region of the porous group was significantly higher than that of the smooth group. However, there was no significant difference among the different $\mathrm{Mg} / \mathrm{Mg}-\mathrm{Cu}$ content groups. The second row presents hard tissue biopsy of the distal femur from five groups after two months. There was an overall decrease in bone volume compared with that after one month.

higher than that of the smooth group in VOI $2(p<0.05)$. In the second month, the overall trend was consistent with that in the first month; however, the fluorescence intensity was marginally low (Fig. 3).

\section{Hard tissue biopsy}

The BV in VOI 2 of the porous group was significantly higher than that of the smooth group. However, there was no significant difference among the different $\mathrm{Mg} / \mathrm{Mg}-\mathrm{Cu}$ content groups, which is consistent with the results of the CT analysis (Fig. 4). The bone growth in VOI 1 was also consistent with the findings of the CT scan.

\section{Discussion}

In the present study, the effects of different proportions of $\mathrm{Mg} /$ $\mathrm{Mg}-\mathrm{Cu}$ coatings on bone ingrowth were investigated. Although the porous structures were better than the smooth structures, $\mathrm{Mg}$ and two proportions of $\mathrm{Mg}-\mathrm{Cu}$ coatings exhibited no obvious effect on osteogenesis compared with that of bare porous structures. However, it has been reported that $\mathrm{Mg}-$ $0.03 \mathrm{Cu}$ and $\mathrm{Mg}-0.19 \mathrm{Cu}$ have a considerable effect on cell adhesion and activity. ${ }^{6}$ This can be attributed to the following reasons. (1) The porous structure itself has a strong bone integration effect, the effect of $\mathrm{Mg}-\mathrm{Cu}$ coating did not exceed that, and therefore the bone formation effect was not obvious. (2) Copper can accelerate the degeneration of $\mathrm{Mg}$ coating; in order to improve the short-term osteogenic ability, the release of $\mathrm{Mg}$ ion can be regulated by elevating the proportion of $\mathrm{Cu}$. Thus, we selected $\mathrm{Mg}-0.1 \mathrm{Cu}$ and $\mathrm{Mg}-0.7 \mathrm{Cu}$ to improve its osteogenic effect. However, the proportion of $\mathrm{Mg}-\mathrm{Cu}$ coating was not the best. Further research in this area should be carried out. (3) With respect to the complicated environment in vivo, the influential factors, such as operative bleeding, flushing, and repeated implant placing, can also affect the results.

In general, the rate of degradation in vivo is 1-5 times less than that in vitro. ${ }^{12}$ In the present study, during the observation period of one month, it was found that osteogenesis in the $\mathrm{Mg}$ -
$\mathrm{Cu}$ groups relatively increased. However, there was no statistical difference when compared with that of the bare porous group. During the second month, the BV decreased relatively. A possible reason for this can be the degradation of coating and weakening of its local function, resulting in callus remolding process (the observation of slices indicated increased callus aggregation). The effect of $\mathrm{Mg}-\mathrm{Cu}$ coating on bone integration was not obvious compared with that of porous structures. Further, the antibacterial effect of $\mathrm{Cu}$ released from the $\mathrm{Mg}-\mathrm{Cu}$ alloys against Staphylococcus aureus in the neutral environment has been verified. ${ }^{6}$ Previous studies have also demonstrated the ability of $\mathrm{Mg}$ against bacterial infection to reduce the risk of implant-associated infection. ${ }^{13}$ The anti-infection effect in the biological fixed surface is also an important advantage; from this perspective, although the effect of $\mathrm{Mg}$-Cu coating on bone integration was not obvious, its antibacterial ability is promising in orthopedic applications. Our unpublished data indicated that $\mathrm{Mg}$ coating can restrain peri-implant osteolysis. In contrast, although the osteogenic ability of $\mathrm{Mg}-\mathrm{Cu}$ coating in this study was not obvious, the ability to inhibit osteoclast favors its use in patients with osteoporosis. Overall, $\mathrm{Mg}-\mathrm{Cu}$ coating may not promote osteogenesis, but can exhibit antibacterial effects and inhibit bone destruction. We conducted an in vivo animal study to evaluate the effects of biodegradable $\mathrm{Mg}-\mathrm{Cu}$ coatings on bone integration. The results of the present study suggest that the application of $\mathrm{Mg}-\mathrm{Cu}$ coating in orthopedic implants is mainly due to its long-term antibacterial ability rather than its osteogenesis ability.

There are some limitations to the present study. First, an in vitro test was not carried out in the present study in order to verify the results obtained in vivo. Second, the degradation time of coating has not been clarified in vivo, and further studies are necessary to elucidate the relationship between time and degradation.

\section{Conclusions}

In the present study, the osteogenic effect of $\mathrm{Mg}-\mathrm{Cu}$ coated implants was compared using a rabbit model. The results 
revealed that the porous structure is more conducive to promote osteogenesis than the smooth structure. Compared with the porous or $\mathrm{Mg}$ group, the $\mathrm{Mg}-0.1 \mathrm{Cu}$ and $\mathrm{Mg}-0.7 \mathrm{Cu}$ groups exhibited no obvious advantage in osteogenesis. The osteogenic application of $\mathrm{Mg}-\mathrm{Cu}$ coating of orthopedic implants is worth further investigation. Furthermore, due to their long-term antibacterial ability, the biodegradable $\mathrm{Mg}-\mathrm{Cu}$ coatings are promising in orthopedic applications.

\section{Conflicts of interest}

The authors declare that there are no conflicts of interest.

\section{Acknowledgements}

This study was supported by the National Key R\&D Program of China (Grant No. 2016YFC1101802, 2016YFC1101804).

\section{References}

1 Y. Zhao, M. I. Jamesh, W. K. Li, G. Wu, C. Wang, Y. Zheng, K. W. Yeung and P. K. Chu, Acta Biomater., 2014, 10, 544-556. 2 H. M. Wong, Y. Zhao, V. Tam, S. Wu, P. K. Chu, Y. Zheng, M. K. To, F. K. Leung, K. D. Luk, K. M. Cheung and K. W. Yeung, Biomaterials, 2013, 34, 9863-9876.

3 J. Walker, S. Shadanbaz, T. B. Woodfield, M. P. Staiger and G. J. Dias, J. Biomed. Mater. Res., Part B, 2014, 102, 1316-1331.
4 S. F. Fischerauer, T. Kraus, X. Wu, S. Tangl, E. Sorantin, A. C. Hanzi, J. F. Loffler, P. J. Uggowitzer and A. M. Weinberg, Acta Biomater., 2013, 9, 5411-5420.

5 L. Strause, P. Saltman and J. Glowacki, Calcif. Tissue Int., 1987, 41, 145-150.

6 C. Liu, X. Fu, H. Pan, P. Wan, L. Wang, L. Tan, K. Wang, Y. Zhao, K. Yang and P. K. Chu, Sci. Rep., 2016, 6, 27374.

7 F. Witte, V. Kaese, H. Haferkamp, E. Switzer, A. MeyerLindenberg, C. J. Wirth and H. Windhagen, Biomaterials, 2005, 26, 3557-3563.

8 R. W. Li, N. T. Kirkland, J. Truong, J. Wang, P. N. Smith, N. Birbilis and D. R. Nisbet, J. Biomed. Mater. Res., Part A, 2014, 102, 4346-4357.

9 W. Liu, M. Cheng, T. Wahafu, Y. Zhao, H. Qin, J. Wang, X. Zhang and L. Wang, J. Mater. Sci.: Mater. Med., 2015, 26, 203.

10 M. L. Bouxsein, S. K. Boyd, B. A. Christiansen, R. E. Guldberg, K. J. Jepsen and R. Muller, J. Bone Miner. Res., 2010, 25, 1468-1486.

11 Z. Du, Z. Zhu and Y. Wang, J. Orthop. Surg. Res., 2018, 13, 23.

12 A. H. Martinez Sanchez, B. J. Luthringer, F. Feyerabend and R. Willumeit, Acta Biomater., 2015, 13, 16-31.

13 Y. Zhao, H. Qin, M. Cheng, Q. Wang, Q. Wang, J. Wang, Y. Jiang, Z. An and X. Zhang, RSC Adv. , 2015, 5, 21434-21444. 